\section{Utility of Diagnostic Whole-Body Iodine Scanning in High-Risk Differentiated Thyroid Carcinoma}

TO THE EDITOR: de Meer et al. recently published a retrospective study comparing diagnostic whole-body scintigraphy (DxWBS) to stimulated thyroglobulin measurement in patients with high-risk differentiated thyroid cancer (1). The authors concluded that DxWBS offered no additional information compared with recombinant human thyroid-stimulating hormone (rhTSH)-stimulated thyroglobulin levels for this cohort of patients. We would argue that shortcomings in the study design and DxWBS methodology invalidate the authors' conclusion.

The authors defined high-risk patients as those with either T3 or T4 tumors or cervical lymph node metastases (N1) based on American Joint Committee on Cancer (AJCC) TNM version 7 (2). Interestingly, they chose to exclude all patients with distant metastases (M1). However, the authors' high-risk definition is inconsistent with both American and European guidelines, which include patients with M1 disease in their definitions of high-risk patients $(3,4)$. Moreover, the inclusion and exclusion criteria may have been stated incorrectly: we were surprised to see AJCC TNM stage II patients listed in Table 1 of the article. AJCC TNM stage II is defined as either M1 disease in patients less than $45 \mathrm{y}$ old or T2N0M0 for patients more than $45 \mathrm{y}$ old. Since both of these subsets of patients were purportedly excluded, stage II patients should not have appeared in the group analyzed. This inconsistency warrants explanation or correction.

The authors did not take into account age when risk stratifying their patients since European treatment guidelines are independent of age. However, age is considered the most important prognostic variable for mortality by the American National Comprehensive Cancer Network guidelines, with higher mortality in patients over $40 \mathrm{y}$ old (5). For papillary and follicular thyroid carcinoma, AJCC TNM staging defines all patients less than $45 \mathrm{y}$ old as either stage I or stage II, including patients with distant metastases. In a study validating AJCC TNM classification and group staging for patients with papillary thyroid carcinoma, age was an independent predictor of both disease-free survival and cause-specific survival (6). Not using the age for risk stratification in such a study renders the results irrelevant to nuclear medicine practices in the United States.

In their study, the authors performed DxWBS with thyroid hormone withdrawal (THW) between January 1998 and December 2004 and then switched to rhTSH exclusively from January 2005 to January 2009. However, the original phase III clinical trial comparing rhTSH and THW preparation for DxWBS concluded that rhTSH DxWBS was less sensitive

COPYRIGHT (c) 2012 by the Society of Nuclear Medicine, Inc. Published online Feb. 8, 2012. than DxWBS using THW (7). In this phase III trial, rhTSH DxWBS was inferior to THW DxWBS in 18 (29\%) of 62 patients and failed to detect metastatic disease in $8(13 \%)$ of 62 patients with positive scans. A second phase III clinical trial, again comparing rhTSH and THW preparation for DxWBS, also showed that rhTSH DxWBS was inferior to THW DxWBS in $8(16 \%)$ of 49 of patients with metastatic disease (8). Although this difference was not statistically significant $(p=0.109)$, the trend favored THW DxWBS. As a result, we believe that rhTSH DxWBS should be reserved for low-risk patients only, an approach supported by the package insert for rhTSH itself. Moreover, the authors waited $7 \mathrm{~d}$ after ${ }^{131} \mathrm{I}$ administration to perform the DxWBS (European guidelines recommend between 2 and 5 d) and used twice the recommended ${ }^{131} \mathrm{I}$ activity; these factors make their technique impossible to compare with standard practices.

Relying on rhTSH-stimulated thyroglobulin for detection of recurrence has its perils. Comparing ${ }^{131} \mathrm{I}$ rhTSH-stimulated DxWBS to thyroglobulin during routine follow-up evaluations, Robbins et al. found metastatic thyroid carcinoma on DxWBS in $13.7 \%$ of patients of all risk categories with stimulated thyroglobulin of $2 \mu \mathrm{g} / \mathrm{L}$ or less (9). The authors of the present paper mentioned the conclusion of Robbins et al. but left a huge gap in the discussion by offering no explanation as to why their own results and conclusions were so different from those of Robbins et al. Only the DxWBS can show iodine avidity and guide the decision on whether to treat the patients with ${ }^{131} \mathrm{I}$ or with surgery. In the United States, DxWBS remains the gatekeeper to more advanced imaging with ${ }^{18} \mathrm{~F}$-FDG PET, as most insurance companies require both elevated thyroglobulin levels and negative DxWBS findings to reimburse PET. Omitting the DxWBS would make ${ }^{18}$ F-FDG PET unavailable to patients in the United States.

The deMeer et al. study addressed a very narrow segment of high-risk thyroid carcinoma patients, did not follow accepted risk stratification guidelines, and does not help many of us who use age in this stratification. The striking deficiencies of this work are the application of rhTSH-stimulated DxWBS to a high-risk group in which it is considered to be inferior to THW DxWBS, the use of nonstandard imaging techniques, and the notion that disease location and iodine avidity are irrelevant to patient management. The readers are encouraged to keep these issues in mind as they evaluate high-risk thyroid cancer patients.

\section{REFERENCES}

1. de Meer SG, Vriens MR, Zelissen PM, Borel Rinkes IH, de Keizer B. The role of routine diagnostic radioiodine whole-body scintigraphy in patients with high-risk differentiated thyroid cancer. J Nucl Med. 2011;52:56-59.

2. Edge SB, Byrd DR, Compton CC, Fritz AG, Greene FL, Trotti A, eds. AJCC Cancer Staging Manual. 7th ed. New York, NY: Springer; 2010:111-122

3. Cooper DS, Doherty GM, Haugen BR, et al. Revised American Thyroid Association management guidelines for patients with thyroid nodules and differentiated thyroid cancer. Thyroid. 2009;19:1167-1214.

4. Pacini F, Schlumberger M, Dralle H, et al. European consensus for the management of patients with differentiated thyroid carcinoma of follicular epithelium. Eur J Endocrinol. 2006;154:787-803. 
5. NCCN guidelines: thyroid carcinoma. National Comprehensive Cancer Network Web site. Available at: http://www.nccn.org/professionals/physician_gls/f_guide lines.asp. Accessed January 30, 2012.

6. Ito Y, Miyauchi A, Jikuzono T, et al. Risk factors contributing to a poor prognosis of papillary thyroid carcinoma: validity of UICC/AJCC TNM classification and stage grouping. World J Surg. 2007;31:838-848.

7. Ladenson PW, Braverman LE, Mazzaferri EL, et al. Comparison of administration of recombinant human thyrotropin with withdrawal of thyroid hormone for radioactive iodine scanning in patients with thyroid carcinoma. N Engl J Med. 1997;337:888-896.

8. Haugen BR, Pacini F, Reiners C, et al. A comparison of recombinant human thyrotropin and thyroid hormone withdrawal for the detection of thyroid remnant or cancer. J Clin Endocrinol Metab. 1999;84:3877-3885.

9. Robbins RJ, Chon JT, Fleisher M, et al. Is serum thyroglobulin response to recombinant human thyrotropin sufficient, by itself, to monitor for residual thyroid carcinoma? J Clin Endocrinol Metab. 2002;87:3242-3247.

\author{
Hung Q. Dam* \\ Timothy A. Manzone \\ Erin C. Grady \\ Mark Tulchinsky \\ *Christiana Care Health System \\ Section of Nuclear Medicine \\ 4755 Ogletown-Stanton Rd. \\ Newark, DE 19718 \\ E-mail:hdam@christianacare.org
}

DOI: 10.2967/jnumed.111.097006

REPLY: We would like to thank our colleagues for their interest in and extensive evaluation of our article (1). We realize that this subject raises questions, and we tried to answer most of them in our article. Dam et al. have some points of criticism that we will address.

We concluded that diagnostic whole-body scintigraphy (DxWBS) offers no additional information in patients with high-risk differentiated thyroid cancer who have undetectable stimulated thyroglobulin either after thyroid hormone withdrawal or recombinant human thyroid-stimulating hormone (rhTSH) stimulation.

An important argument of Dam et al. is that rhTSH-stimulated DxWBS is less sensitive than DxWBS after thyroid hormone withdrawal. However, the study of Robbins et al. (2) showed that the diagnostic accuracy of DxWBS or thyroglobulin between patients prepared by either thyroid hormone withdrawal or rhTSH was comparable. No significant differences were seen in the positive predictive value or negative predictive value. The highest negative predictive value was seen in patients who had low stimulated thyroglobulin levels after rhTSH and negative DxWBS. Furthermore, the use of rhTSH prevents complications after thyroid hormone withdrawal. In our opinion, thyroid hormone withdrawal instead of rhTSH stimulation in preparation for a diagnostic ${ }^{131}$ I scan results in severe hypothyroidism, causing an unnecessary decrease in quality of life. Also, because thyroglobulin measurement (especially after rhTSH) has become extremely sensitive over the last few years, the purpose of additional imaging techniques is not to detect recurrence but to provide anatomic substrate. The use of rhTSHstimulated DxWBS is widely accepted and is the standard of care in The Netherlands.

With the increasing sensitivity of thyroglobulin measurements, we advise against performing routine DxWBS during follow-up.
We are not in favor of completely eliminating diagnostic ${ }^{131} \mathrm{I}$, and we surely do not state that iodine avidity is irrelevant in treating patients with differentiated thyroid cancer, as is stated by our colleagues. We state that other diagnostic and therapeutic steps are preferred over DxWBS. Ultrasound of the neck is an important tool to locate recurrent disease. In patients with elevated thyroglobulin levels, a high dose of radioactive iodine can be administered, for example, and a posttherapeutic scan (RxWBS) performed. This scan is more sensitive than DxWBS and shows iodine avidity of possible metastatic lesions. Whenever this scan is negative, ${ }^{18} \mathrm{~F}$ FDG PET would be another diagnostic method to find an anatomic substrate for the rise in thyroglobulin level.

Other comments of Dam et al. were with respect to the staging of patients in our article.

Patients with M1 disease status were excluded because these patients have a more stringent follow-up regimen. On the basis of additional findings, these patients are treated with surgery or high-dose ${ }^{131}$ I without a prior low-dose scan. DxWBS is never performed on these patients in our clinic, and as a consequence, they could not be included in our analysis. With the results of our current study, we would surely advise against the performance of DxWBS on these patients; instead, we favor treating these patients with therapeutic activities of radioactive iodine followed by RxWBS.

The presence of stage II patients in Table 1 is an error in our article. We apologize for this inconsistency; the distribution of $\mathrm{T}$ and $\mathrm{N}$ stages is shown correctly. Our final conclusion and recommendation are not influenced by this error.

With respect to the comments on age in the staging of patients with differentiated thyroid cancer, we would like to confirm that age is in fact a prognostic factor. However, it is a prognostic factor for disease mortality (which is very low) and not a predictor for recurrence. The risk factors included in our article and both American and European guidelines are based on the risk of recurrence.

Dam et al. imply in their letter that the use of rhTSH DxWBS should be reserved for low-risk patients; however, both American and European guidelines no longer advise DxWBS for low-risk patients. We strongly disagree with Dam et al. on this point, and routine DxWBS should certainly be abandoned in low-risk patients.

In a prior literature study to evaluate the value of DxWBS in high-risk patients, we found no studies that examined high-risk patients only. Several studies analyzed the additional value of DxWBS, but also in low-risk patients (3-10). Most studies found no additional value of DxWBS in their patient group (3-9). Verburg et al. (7) have already suggested that DxWBS should be omitted also in high-risk patients.

The study by Robbins et al. (10), as questioned by Dam et al., favors the use of the diagnostic whole-body scan as a routine procedure for all patients with differentiated thyroid cancer, even low-risk patients. When results were analyzed only for low-risk patients, Robbins et al. found the stimulated thyroglobulin level to have a high negative predictive value, especially when patients had a prior negative WBS result (negative predictive value, $100 \%)$. Still they concluded that analysis of both tests together would result in a better diagnostic accuracy than either test alone. It is unclear if patients with known metastatic disease were included in this analysis. Furthermore, it is noteworthy that none of the patients with metastatic disease had thyroglobulin levels below $0.2 \mathrm{mg} / \mathrm{L}$, which is used as a cutoff point for several other studies. 
Although we disagree with Dam et al. on some matters, we thank them for fine-tuning our data and sharpening the discussion.

\section{REFERENCES}

1. de Meer SG, Vriens MR, Zelissen PM, Borel Rinkes IH, de Keizer B. The role of routine diagnostic radioiodine whole-body scintigraphy in patients with high-risk differentiated thyroid cancer. J Nucl Med. 2011;52:56-59.

2. Robbins RJ, Tuttle RM, Sharaf RN, et al. Preparation by recombinant human thyrotropin or thyroid hormone withdrawal are comparable for the detection of residual differentiated thyroid carcinoma. J Clin Endocrinol Metab. 2001;86: 619-625.

3. Huang SH, Wang PW, Huang YE, et al. Sequential follow-up of serum thyroglobulin and whole body scan in thyroid cancer patients without initial metastasis. Thyroid. 2006;16:1273-1278.

4. Cailleux AF, Baudin E, Travagli JP, Ricard M, Schlumberger M. Is diagnostic iodine-131 scanning useful after total thyroid ablation for differentiated thyroid cancer? J Clin Endocrinol Metab. 2000;85:175-178.

5. Mazzaferri EL, Kloos RT. Is diagnostic iodine-131 scanning with recombinant human TSH useful in the follow-up of differentiated thyroid cancer after thyroid ablation? J Clin Endocrinol Metab. 2002;87:1490-1498.

6. Pacini F, Capezzone M, Elisei R, Ceccarelli C, Taddei D, Pinchera A. Diagnostic 131-iodine whole-body scan may be avoided in thyroid cancer patients who have undetectable stimulated serum $\mathrm{Tg}$ levels after initial treatment. J Clin Endocrinol Metab. 2002;87:1499-1501.

7. Verburg FA, de Keizer B, de Klerk JM, Lentjes EG, Lips CJ, van Isselt JW. Value of diagnostic radioiodine scintigraphy and thyroglobulin measurements after rhTSH injection. Nuklearmedizin. 2009;48:26-29.
8. David A, Blotta A, Bondanelli M, et al. Serum thyroglobulin concentrations and ${ }^{131}$ I whole-body scan results in patients with differentiated thyroid carcinoma after administration of recombinant human thyroid-stimulating hormone. $\mathrm{J} \mathrm{Nucl}$ Med. 2001;42:1470-1475.

9. Pacini F, Molinaro E, Castagna MG, et al. Recombinant human thyrotropinstimulated serum thyroglobulin combined with neck ultrasonography has the highest sensitivity in monitoring differentiated thyroid carcinoma. J Clin Endocrinol Metab. 2003;88:3668-3673.

10. Robbins RJ, Chon JT, Fleisher M, Larson SM, Tuttle RM. Is the serum thyroglobulin response to recombinant human thyrotropin sufficient, by itself, to monitor for residual thyroid carcinoma? J Clin Endocrinol Metab. 2002;87: 3242-3247.

\section{Siegrid G. de Meer*}

Menno R. Vriens

Pierre M. Zelissen

Inne H. Borel Rinkes

Bart de Keizer

*University Medical Center Utrecht

Heidelberglaan 100

Utrecht, The Netherlands 3508 GA

E-mail: s.g.s.demeer-2@umcutrecht.nl

DOI: 10.2967/jnumed.111.097279 